\title{
Peripheral insulin resistance develops in transgenic rats overexpressing phosphoenolpyruvate carboxykinase in the kidney
}

\author{
B. J. Lamont ${ }^{1}$, S. Andrikopoulos ${ }^{1}$, A. Funkat ${ }^{1}$, J. Favaloro ${ }^{1}$, J. M. Ye ${ }^{2}$, E. W. Kraegen ${ }^{2}$, K. F. Howlett ${ }^{3}$, \\ J. D. Zajac ${ }^{4}$, J. Proietto ${ }^{1}$ \\ ${ }^{1}$ University of Melbourne Department of Medicine, Royal Melbourne Hospital, Parkville, Victoria, Australia \\ ${ }^{2}$ Garvan Institute of Medical Research, Sydney, New South Wales, Australia \\ ${ }^{3}$ Deakin University, Melbourne, Victoria, Australia \\ ${ }^{4}$ University of Melbourne Department of Medicine, Austin and Repatriation Medical Centre, Victoria, Australia
}

\section{Abstract}

Aims/hypothesis. To study the secondary consequences of impaired suppression of endogenous glucose production (EGP) we have created a transgenic rat overexpressing the gluconeogenic enzyme phosphoenolpyruvate carboxykinase (PEPCK) in the kidney. The aim of this study was to determine whether peripheral insulin resistance develops in these transgenic rats.

Methods. Whole body rate of glucose disappearance $\left(\mathrm{R}_{\mathrm{d}}\right)$ and endogenous glucose production were measured basally and during a euglycaemic/hyperinsulinaemic clamp in phosphoenolpyruvate carboxykinase transgenic and control rats using $\left[6-{ }^{3} \mathrm{H}\right]$-glucose. Glucose uptake into individual tissues was measured in vivo using 2-[1-14C]-deoxyglucose.

Results. Phosphoenolpyruvate carboxykinase transgenic rats were heavier and had increased gonadal and infrarenal fat pad weights. Under basal conditions, endogenous glucose production was similar in phosphoenolpyruvate carboxykinase transgenic and control rats $(37.4 \pm 1.1$ vs $34.6 \pm 2.6 \mu \mathrm{mol} / \mathrm{kg} / \mathrm{min})$. Moderate hyperinsulinaemia $(810 \mathrm{pmol} / \mathrm{l})$ completely suppressed EGP in control rats $(-0.6 \pm 5.5 \mu \mathrm{mol} / \mathrm{kg} / \mathrm{min}, p<0.05)$ while there was no suppression in phosphoenolpyruvate carboxykinase rats $(45.2 \pm 7.9 \mu \mathrm{mol} / \mathrm{kg} / \mathrm{min})$. Basal
$\mathrm{R}_{\mathrm{d}}$ was comparable between PEPCK transgenic and control rats $(37.4 \pm 1.1$ vs $34.6 \pm 2.6 \mu \mathrm{mol} / \mathrm{kg} / \mathrm{min})$ but under insulin-stimulated conditions the increase in $R_{d}$ was greater in control compared to phosphoenolpyruvate carboxykinase transgenic rats indicative of insulin resistance $(73.4 \pm 11.2$ vs $112.0 \pm 8.0 \mu \mathrm{mol} / \mathrm{kg} / \mathrm{min}$, $p<0.05)$. Basal glucose uptake was reduced in white and brown adipose tissue, heart and soleus while insulin-stimulated transport was reduced in white and brown adipose tissue, white quadriceps, white gastrocnemius and soleus in phosphoenolpyruvate carboxykinase transgenic compared to control rats. The impairment in both white and brown adipose tissue glucose uptake in phosphoenolpyruvate carboxykinase transgenic rats was associated with a decrease in GLUT4 protein content. In contrast, muscle GLUT4 protein, triglyceride and long-chain acylCoA levels were comparable between PEPCK transgenic and control rats.

Conclusions/interpretation. A primary defect in suppression of EGP caused adipose tissue and muscle insulin resistance. [Diabetologia (2003) 46:1338-1347]

Keywords Phosphoenolpyruvate carboxykinase, GLUT4, muscle glucose uptake, adipose tissue glucose uptake, tissue triglycerides, long chain acyl CoA, glycogen.
Received: 25 March 2003 / Revised: 26 May 2003

Published online: 29 July 2003

C) Springer-Verlag 2003

Corresponding author: Prof. J. Proietto, University of Melbourne Department of Medicine, Royal Melbourne Hospital, 3050 Parkville, Victoria, Australia

E-mail: j.proietto@unimelb.edu.au

Abbreviations: EGP, endogenous glucose production; $\mathrm{R}_{\mathrm{d}}$, rate of glucose disappearance; LCACoA, long chain acyl CoA; TG, triglycerides; MCR, metabolic clearance rate.
Insulin resistance is a characteristic feature of Type 2 diabetes. Both reduced insulin-stimulated glucose uptake and metabolism in peripheral tissues (skeletal muscle and fat) and impaired suppression of endogenous glucose production (EGP) by insulin have been documented $[1,2]$.

Multiple mechanisms for the insulin resistance have been proposed including both primary genetic [3, 4] and secondary causes such as nutrient excess [5]. 
The current increase in the prevalence of Type 2 diabetes in many parts of the world [6] is linked to an increase in obesity in the population $[7,8]$. While there could be many causes of insulin resistance, fat-induced defects in insulin action are probably the most important.

Excess fat has been shown to cause peripheral insulin resistance via multiple mechanisms which include among others, excess supply of non-esterified fatty acids [9], increased intracellular accumulation of muscle triglycerides and long chain acyl CoAs (LCACoAs) [9], excessive production of tumor necrosis factor- $\alpha$ [10], reduction in the concentration of adiponectin [11] and increased c-Jun amino-terminal kinase (JNK) activity [12].

Diets high in fat have also been shown to cause impaired insulin suppression of endogenous glucose production $[13,14,15]$. This has been associated with a NEFA-induced increase in gluconeogenesis [15, 16, $17,18]$. Recently, we have confirmed that the dietary fat-induced increase in gluconeogenesis is associated with increased levels of fructose-1,6-bisphosphatase, a regulatory enzyme in the glucose synthesising pathway $[15,19]$. Interestingly, it has been suggested that fat-induced hepatic insulin resistance precedes muscle insulin resistance [13] raising the possibility that hepatic insulin resistance can contribute to muscle and fat insulin resistance observed under states of increased dietary fat intake.

The secondary consequences of impaired suppression of gluconeogenesis have not been formally tested. An increase in glucose production could enhance glucose entry into muscle and fat cells causing 'glucose toxicity', a phenomenon that has been attributed to a number of processes including increased flux through the hexosamine biosynthesis pathway (HBP) $[5,20,21]$ and the intracellular accumulation of triglycerides [22].

To determine the consequences of chronically impaired suppression of gluconeogenesis we have produced transgenic rats that overexpress the regulated enzyme of gluconeogenesis, phosphoenolpyruvate carboxykinase (PEPCK) predominantly in the kidney under the control of a non-insulin responsive promoter [23]. These rats developed a number of features associated with the metabolic syndrome including obesity, mild hyperglycaemia, hyperinsulinaemia, and dyslipidaemia [24]. The aim of this study was to investigate the consequences of impaired EGP regulation on peripheral glucose uptake. We show that an impaired suppression of EGP leads to insulin resistance in muscle and adipose tissue.

\section{Methods}

Animals. PEPCK transgenic rats expressing the PEPCK gene predominantly in the kidney under the control of the metal- lothionein promoter were produced as previously described on the PVG/c background strain. We have previously shown that there is no PEPCK expression in fat, heart, muscle, lung and brain of transgenic rats [23]. The rats were housed in the University of Melbourne, Department of Medicine Animal Research Facility at the Royal Melbourne Hospital. Control rats (PVG/c) were purchased from the Animal Resource Centre (Perth, WA, Australia) at 11 to 12 weeks of age and then housed in the University of Melbourne, Department of Medicine animal facility for 3 weeks. Lighting was artificial and timer controlled with a 12 -h light/dark cycle. Room temperature was kept constant at $22^{\circ} \mathrm{C}$. Rats were fed a standard laboratory chow diet consisting of $74 \%$ carbohydrate, $6 \%$ fat and $20 \%$ protein, by weight (Barastoc Pty, Pakenham, Victoria, Australia). All procedures were approved by the Royal Melbourne Hospital Research Foundation Animal Ethics Committee, approval number AEC 2000.002.

Experimental procedure. After an overnight fast, polyethylene catheters (Crichley Electrical, NSW, Australia) were inserted into the right jugular vein and left carotid artery. The venous catheter was used for infusion and the arterial catheter for blood sampling. A tracheostomy was carried out to prevent upper airway obstruction during the experiment. Anaesthesia was monitored regularly and maintained throughout the experiment by intravenous administration of pentobarbitone sodium (Nembutal, Rhone Merieux, QLD, Australia). Body temperature was monitored with a rectal temperature probe and maintained at $37^{\circ} \mathrm{C}$ with a heating lamp.

Glucose turnover. A primed (2-min, $100 \mu \mathrm{Bq} \cdot \mathrm{min}^{-1}$ ) continuous infusion $\left(5.5 \mu \mathrm{Bq} \cdot \mathrm{min}^{-1}\right)$ of $\left[6^{-3} \mathrm{H}\right]$-glucose was administered during basal and euglycaemic-hyperinsulinaemic clamp experiments to measure whole body glucose turnover [25]. During the hyperinsulinaemic clamp experiments, following an initial priming dose, insulin was infused at a constant rate at either $2 \mathrm{mU} \cdot \mathrm{kg}^{-1} \cdot \mathrm{min}$ in transgenic rats or $4 \mathrm{mU} \cdot \mathrm{kg}^{-1} \cdot \mathrm{min}$ in control rats to produce similar plasma insulin concentrations in the two groups of rats. In a separate group of PEPCK transgenic rats, insulin was infused at the higher $4 \mathrm{mU} \cdot \mathrm{kg}^{-1} \cdot \mathrm{min}$. Blood glucose concentration was maintained by the infusion of a $5 \%$ glucose solution. Blood samples were collected during steady state conditions at 90, 100 and $110 \mathrm{~min}$. Under steady-state conditions the rate of glucose appearance equals the rate of glucose disappearance. The rate of glucose disappearance $\left(\mathrm{R}_{\mathrm{d}}\right)$ was calculated by dividing the infusion rate of $\left[6-{ }^{3} \mathrm{H}\right]$-glucose $\left(\mathrm{dpm} \cdot \mathrm{min}^{-1}\right)$ by the plasma $\left[6^{-3} \mathrm{H}\right]$-glucose specific activity. The rate of endogenous glucose production (EGP) was measured as the difference between the calculated $R_{d}$ and the rate of infused glucose.

Measurement of individual tissue glucose uptake. A modification of the labelled 2-[1-14C]-deoxyglucose technique [26] was used to measure glucose uptake into individual tissues [25]. Following the collection of blood samples for measurement of whole body glucose turnover, a bolus of $2-\left[1-{ }^{14} \mathrm{C}\right]$-deoxyglucose $(370 \mu \mathrm{Bq})$ was injected intravenously and blood samples were collected at 2, 5, 10, 15, 30 and $45 \mathrm{~min}$. Immediately following the collection of the last blood sample at $45 \mathrm{~min}$, the rats were killed by a lethal overdose of pentobarbitone sodium and tissues including heart, diaphragm, quadriceps (red and white), soleus, gastrocnemius (red and white), brown adipose and white adipose tissue were rapidly removed, frozen in liquid nitrogen and stored at $-70^{\circ} \mathrm{C}$ for subsequent analysis. The time course of $2-\left[1-{ }^{14} \mathrm{C}\right]$-deoxyglucose disappearance from plasma and the degree of phosphorylated 2-deoxyglucose accumulation in individual tissues were determined [25]. Glu- 
cose uptake into individual tissues was calculated as previously described [26].

Analysis of Plasma Glucose, Insulin and NEFA The concentration of glucose was measured by the glucose oxidase assay using an automated glucose analyser (YSI 2300 Stat Plus, Yellow Springs Instruments, Yellow Springs, Ohio, USA). Plasma insulin concentrations were measured using a rat insulin radioimmunoassay kit (Linco Research, St. Charles, Mo., USA). Fasting NEFA concentrations were measured in plasma samples that were collected in sequestrene tubes before the infusion of heparin using a colorimetric assay kit (Wako Pure Chemical Industries, Va., USA).

Kidney and liver PEPCK mRNA expression. Total RNA was extracted from kidney and liver using the guanidinium thiocyanate procedure as previously described [23]. RNA was then reverse transcribed using random priming with an AMV reverse transcriptase kit (Promega, Annandale, NSW, Australia). Relative expression of the PEPCK transcript were measured by quantitative Real-Time PCR using SYBR Green (Applied Biosystems, Scoresby, Victoria, Australia) to detect products formed from PEPCK specific primers (PEPCK forward primer 5'-AGTTGAATGTGTGGGTGATGACA-3'; reverse primer 5' AAAACCGTTTTCTGGGTTGATG-3'), which was compared against the product amplified by $\beta$-actin specific primers $(\beta$ actin forward primer $5^{\prime}$-CGTGAAAAGATGACCCAGATCA3'; reverse primer 5'-CACAGCCTGGATGGCTACGT-3').

PEPCK enzyme activity. Kidney and liver was collected in groups of rats that were fasted overnight, but had not been infused with ${ }^{14} \mathrm{C}$ labelled tracer. Tissue samples were homogenised and assayed for PEPCK enzyme activity using the oxaloacetate- $\mathrm{H}^{14} \mathrm{CO}_{3}$ exchange method [27].

Tissue glycogen measurement. Glycogen content was measured in red and white gastrocnemius muscle obtained under basal and hyperinsulinaemic clamp conditions. Muscle was freeze dried, dissected free of visible connective tissue and blood and powdered and glycogen concentrations were determined [28].

Muscle and fat GLUT4 protein content. GLUT4 protein content was measured in muscle and brown and white adipose tissue samples from PEPCK transgenic and control rats using a rabbit polyclonal antibody specific for GLUT4 (R1159) [29].

Tissue triglyceride and LCA-CoA measurement. Muscle samples were collected from PEPCK transgenic and control rats that were fasted overnight and administered a lethal overdose of pentobarbitone sodium. Previously described methods were used to measure the content of triglyceride and long-chain acyl-CoA $[22,30]$ in red and white gastrocnemius.

Statistical analysis. Results are expressed as mean \pm SEM. A non-paired, Student's two-tailed $t$ test was used to determine statistical significance between the means of two sample populations. A $p$ value of less than 0.05 was considered statistically significant.

\section{Results}

Animal characteristics. PEPCK transgenic and control rats of both sexes were studied at approximately 14 weeks of age. At this age, the body weight of both male and female PEPCK transgenic rats was higher than control rats (Table 1). This increase in body weight was accompanied by higher weights of gonadal and infrarenal fat depots in PEPCK transgenic compared to control rats. As there was no sex difference in any glucose metabolism parameters measured, data from male and female rats were pooled.

Plasma glucose, insulin and NEFA concentrations were measured in PEPCK transgenic and control rats during the glucose turnover studies. Under basal conditions plasma glucose concentrations were comparable between PEPCK transgenic and control rats. Basal insulin concentrations tended to be higher in PEPCK transgenic rats but did not reach statistical significance $(p=0.13)$. Despite increased adipose tissue depots, there was no difference in basal plasma NEFA concentrations between PEPCK transgenic and control rats (Table 2).

During the hyperinsulinaemic clamp, exogenous glucose was infused to prevent hypoglycaemia. This resulted in higher plasma glucose concentration in the PEPCK transgenic compared to control rats. To match plasma insulin concentrations during the hyperinsulinaemic clamp, PEPCK transgenic rats were infused with $2 \mathrm{mU} \cdot \mathrm{kg}^{-1} \cdot \mathrm{min}^{-1}$ and control rats were infused at a rate of $4 \mathrm{mU} \cdot \mathrm{kg}^{-1} \cdot \mathrm{min}^{-1}$ insulin. This resulted in comparable plasma insulin concentration between PEPCK transgenic and control rats. This enabled direct comparison of glucose metabolism pa-

Table 1. Body weights and fat-pad weights of PEPCK transgenic and control rats

\begin{tabular}{llllll}
\hline & \multicolumn{2}{l}{ Control } & & \multicolumn{2}{l}{ PEPCK transgenic } \\
\cline { 2 - 3 } \cline { 5 - 6 } & Male & Female & & Male & Female \\
\hline Age (weeks) & $14.1 \pm 0.2$ & $15.2 \pm 0.5$ & & $14.0 \pm 0.9$ & $13.2 \pm 1.3$ \\
Body weight $(\mathrm{g})$ & $258 \pm 5$ & $175 \pm 6$ & & $367 \pm 18^{\mathrm{a}}$ & $205 \pm 7^{\mathrm{a}}$ \\
Fat pads & & & & \\
Epididymal $(\mathrm{g})$ & $1.05 \pm 0.19$ & & & $2.29 \pm 0.49^{\mathrm{a}}$ & \\
Infrarenal $(\mathrm{g})$ & $0.85 \pm 0.70$ & $0.62 \pm 0.07$ & & $3.04 \pm 0.34^{\mathrm{a}}$ & $0.93 \pm 0.10^{\mathrm{a}}$ \\
Periovarian $(\mathrm{g})$ & & $0.53 \pm 0.05$ & & $0.95 \pm 0.13^{\mathrm{a}}$ \\
\hline
\end{tabular}

Values are expressed as means $\pm \operatorname{SEM}(n=6-8) .{ }^{\mathrm{a}} p<0.05$ compared to control rats 
Table 2. Plasma glucose, insulin and NEFA concentrations under basal and hyperinsulinaemic clamp conditions

Control PEPCK transgenic

PEPCK transgenic

(higher insulin infusion rate)

Basal

Plasma glucose (mmol/l)

Plasma insulin (pmol/l)

Plasma NEFA (mmol/l)

Clamp

Plasma glucose (mmol/l)

Plasma insulin (pmol/l)

$\begin{array}{cc}7.1 \pm 0.3 & 7.3 \pm 0.4 \\ 210 \pm 30 & 285 \pm 45 \\ 0.8 \pm 0.1 & 0.8 \pm 0.1 \\ & \\ 6.3 \pm 0.6 & 9.7 \pm 0.4^{\mathrm{a}} \\ 810 \pm 165 & 945 \pm 90\end{array}$

$7.1 \pm 0.3$

$210 \pm 30$

$945 \pm 90$
$6.0 \pm 0.8$

$1260 \pm 150^{\mathrm{a}}$

Values are expressed as means \pm SEM $(n=4-9)$. ${ }^{a} p<0.05$ compared to control rats

A

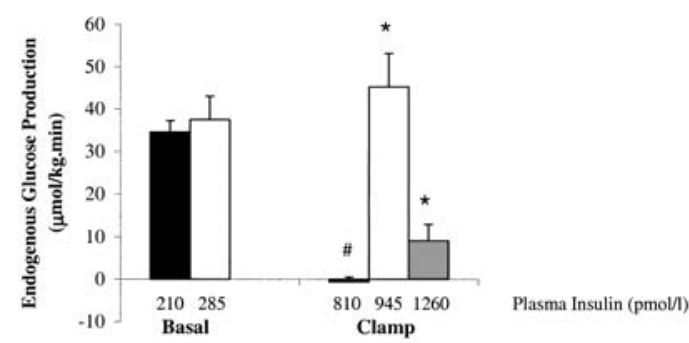

B

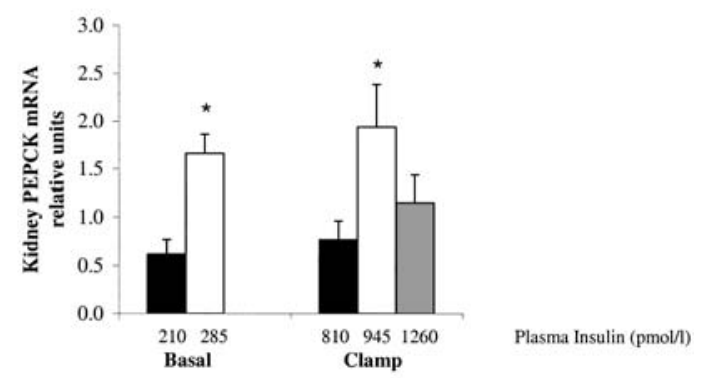

C

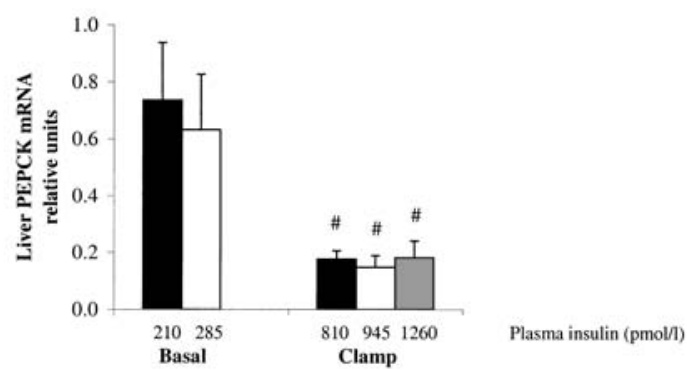

Fig. 1A-C. (A) Endogenous glucose production, (B) kidney PEPCK mRNA and (C) liver PEPCK mRNA under basal and hyperinsulinaemic clamp conditions in PEPCK transgenic (open and grey bars) and control rats (closed bars). Values are presented as means \pm SEM. $* p<0.05$ vs control, $\# p<0.05$ vs basal

rameters between the two groups of rats. A separate group of PEPCK transgenic rats were infused with $4 \mathrm{mU} \cdot \mathrm{kg}^{-1} \cdot \mathrm{min}^{-1}$ insulin (designated as higher insulin infusion rate in Table 2) and the plasma insulin level achieved was $1260 \pm 150 \mathrm{pmol} / 1(p<0.05$ vs $2 \mathrm{mU} \cdot \mathrm{kg}^{-1} \cdot \mathrm{min}^{-1}$ PEPCK transgenic group).

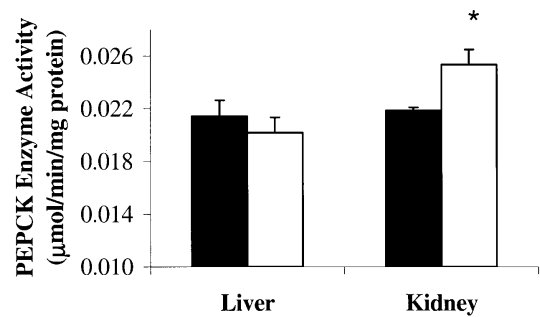

Fig. 2. Liver and kidney PEPCK enzyme activity in PEPCK transgenic (open bars) and control rats (closed bars). Values are presented as means \pm SEM. $* p<0.05$ vs control

Endogenous Glucose Production. Under basal conditions the rate of EGP was comparable between PEPCK transgenic and control rats. During the hyperinsulinaemic clamp, EGP was completely suppressed in control rats, whereas in PEPCK transgenic rats EGP was not different from basal, despite comparable insulin concentrations. Therefore during the hyperinsulinaemic clamp, EGP was increased in PEPCK transgenic compared to control rats. Even at the higher insulin infusion rate EGP was decreased but not completely suppressed in PEPCK transgenic rats (Fig. 1A).

PEPCK $m R N A$ and enzyme activity. PEPCK mRNA was measured in liver and kidney samples obtained from control and PEPCK transgenic rats under basal conditions and following insulin infusion. Kidney PEPCK mRNA was higher in PEPCK transgenic compared to control rats under basal and during insulin infusion conditions (Fig. 1B). This was consistent with the enzyme assay which showed that kidney PEPCK activity was $16 \%$ higher in PEPCK transgenic compared to control rats $(p<0.05$, Fig. 2$)$. Insulin infusion at the higher rate did suppress kidney PEPCK mRNA towards control values in PEPCK transgenic rats (Fig. 1B). In contrast, liver PEPCK mRNA was not different basally and suppressed to similar levels following insulin infusion in both PEPCK transgenic and control rats (Fig. 1C). This suggests that the transgene was not expressed in liver of PEPCK transgenic rats. Furthermore, liver PEPCK enzyme 
A

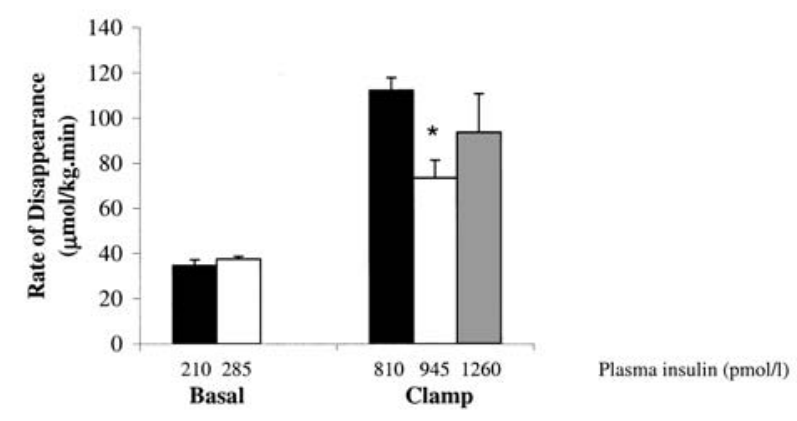

B

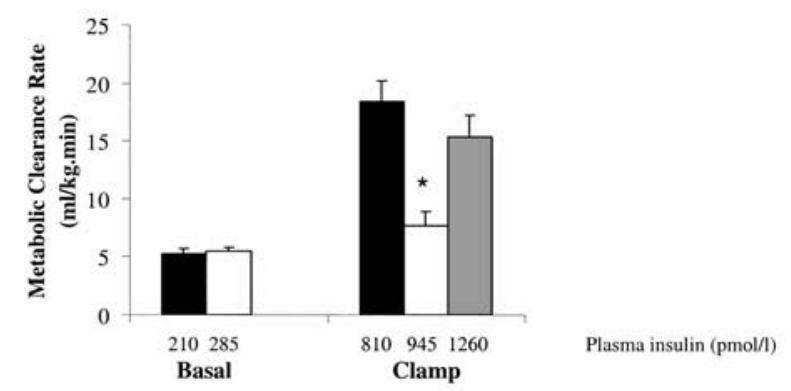

Fig. 3A, B. (A) Rate of glucose disappearance and (B) metabolic clearance rate under basal and hyperinsulinaemic clamp conditions in PEPCK transgenic (open and grey bars) and control rats (closed bars). Values are presented as means \pm SEM. $* p<0.05$ vs control

activity was the same in PEPCK transgenic and control rats (Fig. 2).

Rate of glucose disappearance. During basal conditions there was no difference in the rate of glucose disappearance $\left(\mathrm{R}_{\mathrm{d}}\right)$ between control and PEPCK transgenic rats (Fig. 3A). During the hyperinsulinaemic clamp, the $\mathrm{R}_{\mathrm{d}}$ in PEPCK rats was lower than that in the control rats, indicative of whole body insulin resistance. At the higher plasma insulin concentration, $\mathrm{R}_{\mathrm{d}}$ was not different between PEPCK transgenic and control rats.

As stated earlier, the plasma glucose concentration in the hyperinsulinaemic clamp was higher in the PEPCK transgenic compared to control rats. To account for the mass action effect of glucose on the $R_{d}$, metabolic clearance rate (MCR) was calculated (Fig. 3B). Basal MCR was the same in PEPCK transgenic and control rats. However under hyperinsulinaemic clamp conditions MCR was lower in PEPCK transgenic compared to control rats. MCR was increased with the higher insulin infusion rate in PEPCK transgenic rats such that it was comparable to that achieved at a lower plasma insulin concentration in control rats.

Tissue glucose uptake. To determine the site(s) of insulin resistance in PEPCK transgenic rats, glucose up-

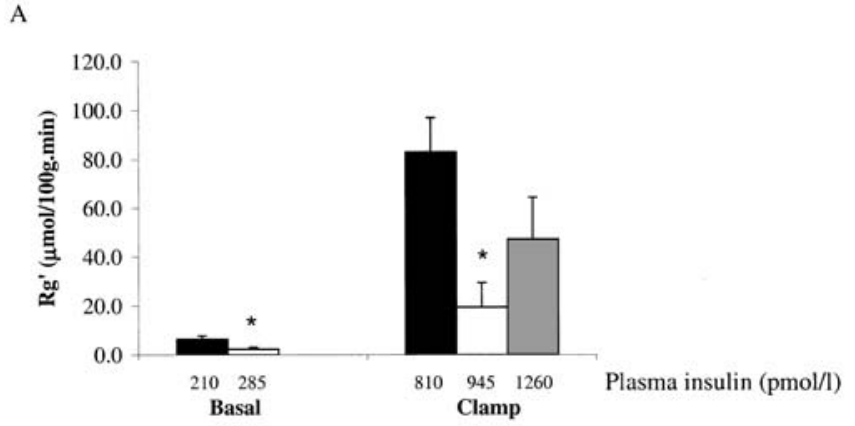

B

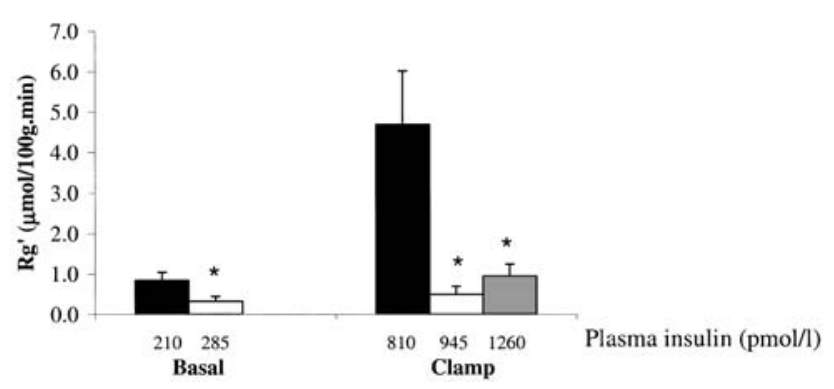

Fig. 4A, B. Rate of glucose uptake in (A) brown adipose tissue and (B) white adipose tissue under basal and hyperinsulinaemic clamp conditions in PEPCK transgenic (open and grey bars) and control rats (closed bars). Values are presented as means \pm SEM. $* p<0.05$ vs control

take into individual tissues was measured using 2-[1$\left.{ }^{14} \mathrm{C}\right]$-deoxyglucose (Table 3, Fig. 4). Compared to basal values, glucose uptake into all tissues was increased in PEPCK transgenic and control animals in response to the hyperinsulinaemic clamp $(p<0.05)$. The only exception was white adipose tissue of PEPCK transgenic rats, which was completely unresponsive to the stimulatory effects of insulin.

Under basal conditions the rate of glucose uptake into heart, diaphragm, red quadriceps, soleus, white and brown adipose tissue was lower in PEPCK transgenic than control rats, while uptake into the other tissues (white quadriceps, red and white gastrocnemius) was comparable between the two groups).

During the hyperinsulinaemic clamp, the rate of glucose uptake into white quadriceps and gastrocnemius, soleus and white and brown adipose tissue was lower in PEPCK transgenic compared to control rats while uptake into other tissues (heart, diaphragm, red quadriceps and gastrocnemius) was comparable between the two groups of rats. Insulin resistance persisted in white gastrocnemius, soleus and white adipose tissue even at the higher insulin infusion rate in PEPCK transgenic compared to control rats (Table 3, Fig. 4).

Muscle glycogen content. Glycogen content was measured in red gastrocnemius (which showed comparable glucose uptake between PEPCK transgenic and 
Table 3 Glucose uptake rates ( $\mu \mathrm{mol} / 100$ g.min) into individual tissues under basal and hyperinsulinaemic clamp conditions

\begin{tabular}{|c|c|c|c|c|c|}
\hline & \multicolumn{2}{|l|}{ Basal } & \multicolumn{2}{|l|}{ Clamp } & \multirow{2}{*}{$\begin{array}{l}\text { Higher insulin infusion rate } \\
\text { PEPCK transgenic }\end{array}$} \\
\hline & Control & $\begin{array}{l}\text { PEPCK } \\
\text { transgenic }\end{array}$ & Control & $\begin{array}{l}\text { PEPCK } \\
\text { transgenic }\end{array}$ & \\
\hline Heart & $6.7 \pm 1.7$ & $2.8 \pm 0.4^{b}$ & $23.8 \pm 4.3^{\mathrm{a}}$ & $26.2 \pm 8.3^{\mathrm{a}}$ & $26.7 \pm 5.7^{a}$ \\
\hline Diaphragm & $7.5 \pm 1.8$ & $3.3 \pm 0.9^{b}$ & $38.1 \pm 6.6^{\mathrm{a}}$ & $22.4 \pm 5.0^{\mathrm{a}}$ & $22.6 \pm 5.2^{\mathrm{a}}$ \\
\hline Red quadriceps & $3.6 \pm 0.8$ & $1.7 \pm 0.3^{\mathrm{b}}$ & $15.5 \pm 1.2^{\mathrm{a}}$ & $13.0 \pm 3.8^{\mathrm{a}}$ & $10.5 \pm 2.9^{a}$ \\
\hline White gastrocnemius & $1.3 \pm 0.1$ & $1.1 \pm 0.1$ & $6.2 \pm 0.8^{a}$ & $3.0 \pm 0.5^{\mathrm{ab}}$ & $3.2 \pm 0.9^{\mathrm{ab}}$ \\
\hline Soleus & $2.2 \pm 0.3$ & $1.4 \pm 0.3^{b}$ & $10.3 \pm 2.1^{\mathrm{a}}$ & $4.7 \pm 0.7 \mathrm{ab}$ & $5.4 \pm 2.2^{\mathrm{ab}}$ \\
\hline
\end{tabular}

Values are expressed as means $\pm \operatorname{SEM}(n=4-9) .{ }^{\mathrm{a}} p<0.05$ compared to basal; ${ }^{\mathrm{b}} p<0.05$ compared to control

Table 4 Muscle glycogen content $\left(\mu \mathrm{mol} \cdot \mathrm{g}^{-1}\right)$ under basal and hyperinsulinaemic clamp conditions

Control PEPCK transgenic PEPCK transgenic

(higher insulin infusion rate)

Red gastrocnemius

Basal

Insulin

$62.6 \pm 13.5$

$117.2 \pm 15.5^{\mathrm{a}}$

$63.2 \pm 15.1$

$114.2 \pm 12.3^{\mathrm{a}}$

$122.6 \pm 8.8^{\mathrm{a}}$

White gastrocnemius

Basal

$58.2 \pm 13.8$

$113.2 \pm 13.7^{\mathrm{a}}$

$73.7 \pm 9.5$

$143.7 \pm 5.3^{\mathrm{a}}$

$147.6 \pm 26.4^{\mathrm{a}}$

Values are expressed as means $\pm \operatorname{SEM}(n=4-5) .{ }^{\mathrm{a}} p<0.05$ compared to basal

control rats) and white gastrocnemius (which showed reduced glucose uptake in PEPCK transgenic compared to control rats) under basal and hyperinsulinaemic clamp conditions (Table 4). Glycogen content of both red and white gastrocnemius muscle was the same in control and PEPCK transgenic rats under basal conditions. Insulin infusion caused an increase in muscle glycogen content in both PEPCK transgenic and control rats but there was no difference in insulin-stimulated glycogen accumulation between the two groups.

Muscle triglyceride and long-chain acyl-CoA content. To further investigate other possible causes of reduced insulin muscle sensitivity, triglyceride and long-chain acyl-CoA content was measured in red and white gastrocnemius from PEPCK transgenic and control rats under basal conditions (Table 5). The triglyceride content of both white and red gastrocnemius was lower in PEPCK transgenic compared to control rats. Longchain acyl-CoA content of both gastrocnemius muscles was the same between transgenic and control rats.

Muscle and adipose tissue GLUT4 protein content. Total GLUT4 protein content was determined in red and white gastrocnemius and in white and brown adipose tissue from PEPCK transgenic and control animals (Fig. 5). There was no difference in total GLUT4
Table 5 Muscle triglyceride $\left(\mu \mathrm{mol} \cdot \mathrm{g}^{-1}\right)$ and long chain acyl CoA (LCACoA nmol.g ${ }^{-1}$ ) content under basal conditions in PECK transgenic and control rats

\begin{tabular}{lrc}
\hline & Control & PEPCK transgenic \\
\hline Triglyceride & & \\
Red gastrocnemius & $2.0 \pm 0.2$ & $1.3 \pm 0.1^{\mathrm{a}}$ \\
White gastrocnemius & $6.4 \pm 1.4$ & $2.7 \pm 1.1^{\mathrm{a}}$ \\
LCACoA & & \\
Red gastrocnemius & $16.9 \pm 1.7$ & $17.8 \pm 1.5$ \\
White gastrocnemius & $6.4 \pm 1.0$ & $6.2 \pm 0.8$ \\
\hline
\end{tabular}

Values are expressed as mean $\pm \operatorname{SEM}(n=4-5)$. a $p<0.05$ compared to control

content in red or white gastrocnemius muscle between PEPCK transgenic and control animals. In contrast, in the more severely insulin-resistant adipose tissue from PEPCK transgenic rats, total GLUT4 was reduced by $59 \%$ in white fat $(p<0.001)$ and by $30 \%$ in brown adipose tissue compared to control rats $(p<0.001)$.

\section{Discussion}

Insulin resistance is an early defect in the development of Type 2 diabetes. The increase in the incidence 
$\mathbf{A}$
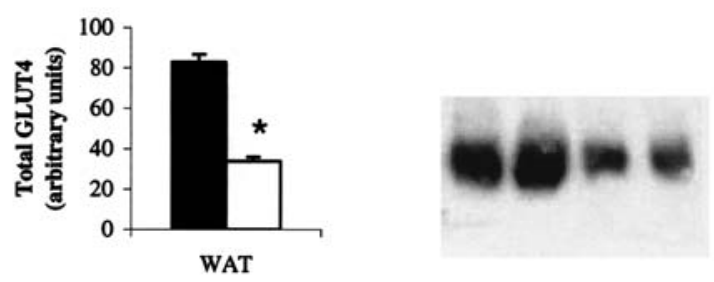

B
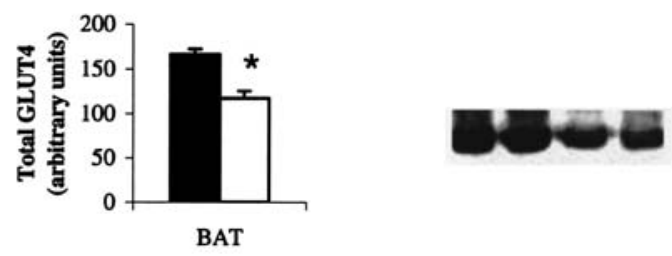

C
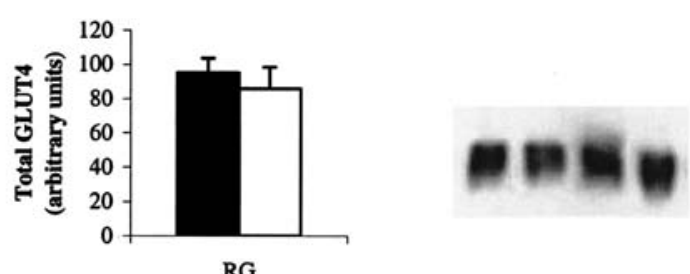

D
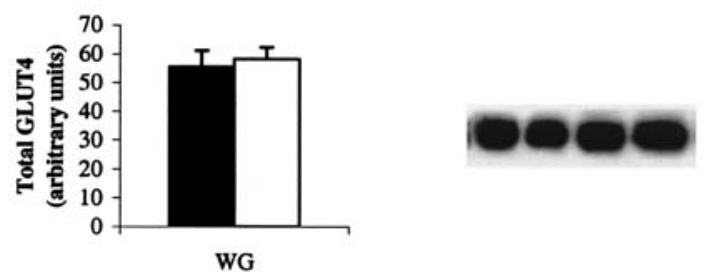

Fig. 5A-D. GLUT4 protein content in (A) white adipose tissue (WAT), (B) brown adipose tissue (BAT), (C) red gastrocnemius (RG) and (D) white gastrocnemius (WG) in PEPCK transgenic (open bars) and control rats (closed bars). Values are presented as means \pm SEM. $* p<0.001$ vs control

of insulin resistance and Type 2 diabetes in many societies is thought to be due to changes in diet and lifestyle [6]. A diet high in fat has been shown to reduce insulin-stimulated glucose uptake and to impair suppression of EGP [13, 14]. Furthermore, it has been suggested that the defect in the suppression of EGP by insulin precedes the defect in insulin action in peripheral tissues [13]. While a high-fat diet might cause peripheral insulin resistance by direct effects on muscle and adipose tissue, the effect of high fat to stimulate gluconeogenesis $[15,16,17,18]$ could have more consequences than simply impaired suppression of endogenous glucose output, as chronic impaired suppression of glucose production leads to obesity and peripheral insulin resistance.

PEPCK has been proposed to be an important regulatory enzyme of gluconeogenesis [32]. In support of this we have previously shown that over-expression of
PEPCK in a rat hepatoma cell line led to increased glucose production [33]. Furthermore transgenic mice overexpressing liver PEPCK showed increased glucose production, hyperglycaemia, hyperinsulinaemia and glucose intolerance [34, 35]. The transgenic rats used in this study over-express PEPCK predominantly in the kidney under the control of a non-insulin responsive promoter [23] and resulted in impaired suppression of EGP during an hyperinsulinaemic clamp. Thus the same concentration of plasma insulin that resulted in complete suppression in control rats was unable to suppress EGP from basal values in the PEPCK transgenic rats. In fact, even at a higher insulin infusion rate, EGP was not completely suppressed in the transgenic rats, which is indicative of the importance of PEPCK to the regulation of gluconeogenesis. Like liver PEPCK over-expressing mice [35], renal PEPCK mRNA was more than twice as high in the transgenic compared to wild-type rats. However PEPCK enzyme activity measured in the basal state was increased only by $16 \%$. It can be concluded therefore that even a modest increase of renal PEPCK activity can have major consequences if no suppression occurs when insulin concentrations are increased post-prandially. Enzyme activity was not measured in the liver over-expressing mice [35].

Interestingly moderate increase of insulin suppressed liver, but not kidney, PEPCK mRNA in both the PEPCK transgenic and control rats. As has been previously suggested [32], this implies that kidney PEPCK is not as insulin responsive as liver PEPCK and that increased renal glucose production can be a substantial contributor to glucose turnover [36, 37]. It has been shown that in patients undergoing liver transplantation endogenous glucose production falls about $50 \%$ after removal of the liver, representing renal glucose production [38]. Indeed it has been suggested that if gluconeogenesis accounts for approximately $50 \%$ of endogenous glucose production in the postabsorptive state [39], that the kidney accounts for approximately $40 \%$ of overall gluconeogenesis [40]. Early studies in animals showed an increase in the rate of glucose infusion required to maintain euglycaemia when the liver and kidneys were removed as compared to when only the liver was excised [41, 42]. Furthermore experimental diabetes in animals results in increased renal gluconeogenesis and glucose production in vitro [43, 44]. Recently increased renal glucose production has been described in patients with Type 2 diabetes which could contribute to the ensuing hyperglycaemic state [45].

Impaired suppression of EGP led to peripheral insulin resistance with $R_{d}$ being reduced in our PEPCK transgenic compared to control rats. This is in contrast to transgenic liver PEPCK overexpressing mice which did not show a decrease in $\mathrm{R}_{\mathrm{d}}$ compared to wild-type [35]. This might be due to species differences (rat vs mouse) or to a difference in the tissue in which PEP- 
CK is over-expressed (liver vs kidney). To determine the site(s) responsible for insulin resistance we measured glucose uptake in individual tissues using radioactively labelled 2-deoxyglucose. We found that adipose tissue was the most resistant tissue. Skeletal muscle sensitivity was differentially affected in the transgenic rats. Thus insulin-stimulated glucose uptake was lower in white but not red quadriceps and gastrocnemius muscles. While the metabolic differences between red, which is predominantly oxidative, and white skeletal muscle, which is predominantly glycolytic, have been well characterised [46], the soleus, a pure red muscle did demonstrate insulin resistance. The difference in the responsiveness of different muscles remains unclear.

The decrease in white and brown adipose tissue glucose uptake was associated with reduced GLUT4 protein content in PEPCK transgenic compared to control rats. GLUT4 is predominantly present in muscle and adipose tissue and is responsible for glucose transport during insulin stimulation [47]. In contrast, muscle GLUT4 protein content was not different between the two groups of rats, despite white gastrocnemius muscle being insulin resistant in the PEPCK transgenic rats. This tissue-specific reduction of GLUT4 is similar to that reported in patients with Type 2 diabetes with a decrease in adipose tissue but normal skeletal muscle GLUT4 content [48, 49, 50]. Tissue-specific regulation of GLUT4 has also been described in animals fed a high fat diet, which resulted in decreased GLUT4 mRNA expression in white adipose tissue but not skeletal muscle [51, 52]. Further analysis has suggested that the defect in muscle glucose uptake in patients with Type 2 diabetes could be associated with impairments in trafficking and/or translocation of GLUT4 to the plasma membrane [53, $54,55]$. In agreement, high fat-induced skeletal muscle insulin resistance in animals has been associated with defects in the translocation and intrinsic activity of GLUT4. Therefore in our PEPCK transgenic rats insulin resistance in white and brown adipose tissue is associated with decreased GLUT4 protein content. However insulin resistance in skeletal muscle of the PEPCK transgenic rats was not associated with a reduction in the amount of GLUT4 but could be due to defects in trafficking and/or translocation of this glucose transporter.

Muscle triglyceride and LCACoA levels, which have been associated with insulin resistance [9, 22], were also not different between PEPCK transgenic and control rats. Furthermore, given that muscle insulin resistance was selective and relatively mild (compared to the adipose tissue), we suggest that it was the decrease in adipose tissue glucose uptake that was primarily responsible for the reduction in the rate of whole body glucose disposal and consequently insulin resistance in our PEPCK transgenic rats. In support of this, mice with a specific deletion in adipose tissue
GLUT4 also developed glucose intolerance and whole body insulin resistance [56].

In conclusion, we have shown that a defect in the suppression of endogenous glucose production can secondarily lead to peripheral insulin resistance. Although there is no evidence that increased PEPCK activity is a mechanism for impaired suppression of endogenous glucose production in human diabetes, it has been shown that high fat availability stimulates gluconeogenesis $[18,57,58]$. Thus it is possible that fat can cause peripheral insulin resistance not only by direct effects on muscle and adipose tissue but secondarily by stimulation of gluconeogenesis.

Acknowledgements. We would like to thank Mr. P. Brazodurro for excellent technical assistance. This work was supported by a grant from the National Health and Medical Research Council of Australia (No 970393), and from a Grant-in-Aid from the Diabetes Australia Research Trust.

\section{References}

1. DeFronzo RA, Bonadonna RC, Ferrannini E (1992) Pathogenesis of NIDDM. A balanced overview. Diabetes Care 15:318-368

2. Shulman GI (2000) Cellular mechanisms of insulin resistance. J Clin Invest 106:171-176

3. Groop L (2000) Genetics of the metabolic syndrome. Br J Nutr 83 [Suppl 1]:S39-S48

4. Stern MP (2000) Strategies and prospects for finding insulin resistance genes. J Clin Invest 106:323-327

5. Proietto J, Filippis A, Nakhla C, Clark S (1999) Nutrientinduced insulin resistance. Mol Cell Endocrinol 151: 143-149

6. Zimmet P, Alberti KG, Shaw J (2001) Global and societal implications of the diabetes epidemic. Nature 414:782-787

7. Haffner SM (2000) Obesity and the metabolic syndrome: the San Antonio Heart Study. Br J Nutr 83 [Suppl 1]:S67S70

8. McCarty MF (2000) Toward practical prevention of type 2 diabetes. Med Hypotheses 54:786-793

9. Kraegen EW, Cooney GJ, Ye JM, Thompson AL, Furler SM (2001) The role of lipids in the pathogenesis of muscle insulin resistance and beta cell failure in type II diabetes and obesity. Exp Clin Endocrinol Diabetes 109:S189-S201

10. Hotamisligil GS (2000) Molecular mechanisms of insulin resistance and the role of the adipocyte. Int $\mathrm{J}$ Obes Relat Metab Disord 24 [Suppl 4]:S23-S27

11. Weyer C, Funahashi T, Tanaka S et al. (2001) Hypoadiponectinemia in obesity and type 2 diabetes: close association with insulin resistance and hyperinsulinemia. J Clin Endocrinol Metab 86:1930-1935

12. Hirosumi J, Tuncman G, Chang L et al. (2002) A central role for JNK in obesity and insulin resistance. Nature 420:333-336

13. Kraegen EW, Clark PW, Jenkins AB, Daley EA, Chisholm DJ, Storlien LH (1991) Development of muscle insulin resistance after liver insulin resistance in high-fat-fed rats. Diabetes 40:1397-1403

14. Oakes ND, Cooney GJ, Camilleri S, Chisholm DJ, Kraegen EW (1997) Mechanisms of liver and muscle insulin resistance induced by chronic high-fat feeding. Diabetes 46:1768-1774 
15. Song S, Andrikopoulos S, Filippis C, Thorburn AW, Khan D, Proietto J (2001) Mechanism of fat-induced hepatic gluconeogenesis: effect of metformin. Am J Physiol Endocrinol Metab 281:E275-E282

16. Williamson JR, Kreisberg RA, Felts PW (1966) Mechanism for the stimulation of gluconeogenesis by fatty acids in perfused rat liver. Proc Natl Acad Sci USA 56:247-254

17. Blumenthal SA (1983) Stimulation of gluconeogenesis by palmitic acid in rat hepatocytes: evidence that this effect can be dissociated from the provision of reducing equivalents. Metabolism 32:971-976

18. Roden M, Stingl H, Chandramouli V et al. (2000) Effects of free fatty acid elevation on postabsorptive endogenous glucose production and gluconeogenesis in humans. Diabetes 49:701-707

19. Andrikopoulos S, Proietto J (1995) The biochemical basis of increased hepatic glucose production in a mouse model of type 2 (non-insulin-dependent) diabetes mellitus. Diabetologia 38:1389-1396

20. Filippis A, Clark S, Proietto J (1997) Increased flux through the hexosamine biosynthesis pathway inhibits glucose transport acutely by activation of protein kinase $\mathrm{C}$. Biochem J 324:981-985

21. Filippis C, Filippis A, Clark S, Proietto J (2002) Activation of PI 3-kinase by the hexosamine biosynthesis pathway. Mol Cell Endocrinol 194:29

22. Laybutt DR, Schmitz-Peiffer C, Saha AK, Ruderman NB, Biden TJ, Kraegen EW (1999) Muscle lipid accumulation and protein kinase $\mathrm{C}$ activation in the insulin-resistant chronically glucose-infused rat. Am J Physiol 277:E1070 E1076

23. Rosella G, Zajac JD, Baker L et al. (1995) Impaired glucose tolerance and increased weight gain in transgenic rats overexpressing a non-insulin-responsive phosphoenolpyruvate carboxykinase gene. Mol Endocrinol 9:1396-1404

24. Thorburn AW, Baldwin ME, Rosella G et al. (1999) Features of syndrome $\mathrm{X}$ develop in transgenic rats expressing a non-insulin responsive phosphoenolpyruvate carboxykinase gene. Diabetologia 42:419-426

25. Nolan CJ, Proietto J (1994) The feto-placental glucose steal phenomenon is a major cause of maternal metabolic adaptation during late pregnancy in the rat. Diabetologia 37:976-984

26. Kraegen EW, James DE, Jenkins AB, Chisholm DJ (1985) Dose-response curves for in vivo insulin sensitivity in individual tissues in rats. Am J Physiol 248:E353-E362

27. Andrikopoulos S, Rosella G, Gaskin E et al. (1993) Impaired regulation of hepatic fructose-1,6-bisphosphatase in the New Zealand obese mouse model of NIDDM. Diabetes 42:1731-1736

28. Passonneau JV, Lauderdale VR (1974) A comparison of three methods of glycogen measurement in tissues. Anal Biochem 60:405-412

29. Kelada AS, Macaulay SL, Proietto J (1992) Cyclic AMP acutely stimulates translocation of the major insulin-regulatable glucose transporter GLUT4. J Biol Chem 267: 7021-7025

30. Antinozzi PA, Segall L, Prentki M, McGarry JD, Newgard CB (1998) Molecular or pharmacologic perturbation of the link between glucose and lipid metabolism is without effect on glucose-stimulated insulin secretion. A re-evaluation of the long-chain acyl-CoA hypothesis. J Biol Chem 273: 16146-16154

31. Proietto J, Harewood M, Aitken P, Nankervis A, Caruso G, Alford F (1982) Validation of a practical in vivo insulin dose-response curve in man. Metabolism 31:354-361
32. Hanson RW, Reshef L (1997) Regulation of phosphoenolpyruvate carboxykinase (GTP) gene expression. Annu Rev Biochem 66:581-611

33. Rosella G, Zajac JD, Kaczmarczyk SJ, Andrikopoulos S, Proietto J (1993) Impaired suppression of gluconeogenesis induced by overexpression of a noninsulin-responsive phosphoenolpyruvate carboxykinase gene. Mol Endocrinol 7:1456-1462

34. Valera A, Pujol A, Pelegrin M, Bosch F (1994) Transgenic mice overexpressing phosphoenolpyruvate carboxykinase develop non-insulin-dependent diabetes mellitus. Proc Natl Acad Sci USA 91:9151-9154

35. Sun Y, Liu S, Ferguson S et al. (2002) Phosphoenolpyruvate carboxykinase overexpression selectively attenuates insulin signaling and hepatic insulin sensitivity in transgenic mice. J Biol Chem 277:23301-23307

36. Stumvoll M, Chintalapudi U, Perriello G, Welle S, Gutierrez O, Gerich J (1995) Uptake and release of glucose by the human kidney. Postabsorptive rates and responses to epinephrine. J Clin Invest 96:2528-2533

37. Stumvoll M, Meyer C, Mitrakou A, Nadkarni V, Gerich JE (1997) Renal glucose production and utilization: new aspects in humans. Diabetologia 40:749-757

38. Joseph SE, Heaton N, Potter D, Pernet A, Umpleby MA, Amiel SA (2000) Renal glucose production compensates for the liver during the anhepatic phase of liver transplantation. Diabetes 49:450-456

39. Chandramouli V, Ekberg K, Schumann WC, Kalhan SC, Wahren J, Landau BR (1997) Quantifying gluconeogenesis during fasting. Am J Physiol 273:E1209-E1215

40. Gerich JE, Meyer C, Woerle HJ, Stumvoll M (2001) Renal gluconeogenesis: its importance in human glucose homeostasis. Diabetes Care 24:382-391

41. Bergman H, Drury DR (1938) The relationship of kidney function to the glucose utilization fo the extra abdominal tissues. Am J Physiol 124:279-284

42. Reinecke R (1943) The kidney as a source of glucose in the eviscerated rat. Am J Physiol 140:276-285

43. Teng C (1954) Studies on carbohydrate metabolism in rat kidney slices. II. Effects of alloxan diabetes and insulin administration on glucose uptake and formation. Arch Biochem Biophys 48:415-423

44. Landau B (1960) Gluconeogenesis and pyruvate metabolism in rat kidney in vitro. Endocrinology 67:744-751

45. Meyer C, Stumvoll M, Nadkarni V, Dostou J, Mitrakou A, Gerich J (1998) Abnormal renal and hepatic glucose metabolism in type 2 diabetes mellitus. J Clin Invest 102: 619-624

46. Pette D, Staron RS (1990) Cellular and molecular diversities of mammalian skeletal muscle fibers. Rev Physiol Biochem Pharmacol 116:1-76

47. Olson AL, Pessin JE (1996) Structure, function, and regulation of the mammalian facilitative glucose transporter gene family. Annu Rev Nutr 16:235-256

48. Pedersen O, Bak JF, Andersen PH et al. (1990) Evidence against altered expression of GLUT1 or GLUT4 in skeletal muscle of patients with obesity or NIDDM. Diabetes 39: 865-870

49. Garvey WT, Maianu L, Hancock JA, Golichowski AM, Baron A (1992) Gene expression of GLUT4 in skeletal muscle from insulin-resistant patients with obesity, IGT, GDM, and NIDDM. Diabetes 41:465-475

50. Garvey WT, Maianu L, Huecksteadt TP, Birnbaum MJ, Molina JM, Ciaraldi TP (1991) Pretranslational suppression of a glucose transporter protein causes insulin resistance in adipocytes from patients with non-insulin-dependent diabetes mellitus and obesity. J Clin Invest 87:1072-1081 
51. Ikemoto S, Thompson KS, Itakura H, Lane MD, Ezaki O (1995) Expression of an insulin-responsive glucose transporter (GLUT4) minigene in transgenic mice: effect of exercise and role in glucose homeostasis. Proc Natl Acad Sci USA 92:865-869

52. Han DH, Hansen PA, Host HH, Holloszy JO (1997) Insulin resistance of muscle glucose transport in rats fed a high-fat diet: a reevaluation. Diabetes 46:1761-1767

53. Kelley DE, Mintun MA, Watkins SC et al. (1996) The effect of non-insulin-dependent diabetes mellitus and obesity on glucose transport and phosphorylation in skeletal muscle. J Clin Invest 97:2705-2713

54. Zierath JR, He L, Guma A, Odegoard Wahlstrom E, Klip A, Wallberg-Henriksson H (1996) Insulin action on glucose transport and plasma membrane GLUT4 content in skeletal muscle from patients with NIDDM. Diabetologia 39:1180-1189
55. Garvey WT, Maianu L, Zhu JH, Brechtel-Hook G, Wallace P, Baron AD (1998) Evidence for defects in the trafficking and translocation of GLUT4 glucose transporters in skeletal muscle as a cause of human insulin resistance. J Clin Invest 101:2377-2386

56. Abel ED, Peroni O, Kim JK et al. (2001) Adipose-selective targeting of the GLUT4 gene impairs insulin action in muscle and liver. Nature 409:729-733

57. Chen X, Iqbal N, Boden G (1999) The effects of free fatty acids on gluconeogenesis and glycogenolysis in normal subjects. J Clin Invest 103:365-372

58. Boden G, Chen X, Capulong E, Mozzoli M (2001) Effects of free fatty acids on gluconeogenesis and autoregulation of glucose production in type 2 diabetes. Diabetes 50: $810-816$ 